\title{
Spontaneous broad ligament haematoma following a normal vaginal delivery: a case report
}

\author{
Dheeraj Yalla, Alka N. Nadar*, G. Usha Rani
}

Department of Obstetrics and Gynecology, Sri Ramachandra Medical College, Chennai, Tamil Nadu, India

Received: 12 April 2018

Accepted: 05 May 2018

\section{*Correspondence:}

Dr. Alka N. Nadar,

E-mail: alka.nadar1988@gmail.com

Copyright: () the author(s), publisher and licensee Medip Academy. This is an open-access article distributed under the terms of the Creative Commons Attribution Non-Commercial License, which permits unrestricted non-commercial use, distribution, and reproduction in any medium, provided the original work is properly cited.

\begin{abstract}
Broad ligament haematoma is a rare complication following a normal vaginal delivery. We report one such case of a woman who developed this complication within $3 \mathrm{hrs}$ of normal vaginal delivery. She is G2P1L1, 38 wks GA, in active labour. Pt was allowed for spontaneous progression of labour, following which she delivered vaginally. Within $3 \mathrm{hrs}$ patient looked clinically very pale with vitals being deranged and complains of inability to void urine, severe perineal pain. On basis of clinical examination and transabdominal ultrasound features a diagnosis of right sided broad ligament haematoma was made. Based on patients haemodynamic instability surgical management in the form of obstetric hysterectomy was done.
\end{abstract}

Keywords: Broad ligament haematoma, Hysterectomy, Normal vaginal delivery

\section{INTRODUCTION}

Broad ligament haematoma is a very rare event following a sponatneous vaginal delivery with an incidence of 1 : $20,000 .{ }^{1}$ Haematomas are localized collection of blood outside the blood vessels. Usually these haematomas are the results of upper vaginal, cervical or uterine tears extending into uterine or vaginal arteries.

Most of the haematomas occur due to trauma to the veins. Various predisposing factors like precipitate labour, ceaserean delivery, operative vaginal delivery or trauma to the abdomen, prolonged second stage of labour, macrosomia has been discussed in the literature. ${ }^{2}$ Para genital haematomas are of 2 types.

Supralevator and infralevator. Infralevator haematomas are vulval or vulvovaginal haematomas. They classically present with vaginal symptoms. However, Supralevator haematomas spread upwards and outwards beneath the broad ligament.

\section{Classical symptoms}

Pain: excessive perineal pain is a hallmark symptom, its presence should prompt pelvic examination, restlessness, rectal tenesmus (constant need to empty bowels) within a few hours after birth, collapse in cases of large haematoma.

\section{Rare symptoms}

Retention of urine, unexplained pyrexia. Signs of hypovolaemia: collapse, shock: elevated pulse, decreased $\mathrm{BP}$, pale, sweaty, clammy, sudden drop in haematocrit level. ${ }^{3}$

\section{Abdominal examination}

Uterus is deviated upward and laterally, to the opposite side from the broad ligament haematoma. 
DD: pelvic mass: abscess intra-abdominal bleeding. Blood tests CBC, Coagulation studies, blood grouping and cross matching to be done.

Imaging studies: transabdominal USG, CT and MRI for diagnosing haematomas, its location, size and extent.

Management: first line - resuscitation - iv fluids and blood transfusion. Conservative management in the form of broad spectrum antibiotics and continuous monitoring can be done if the haematomas $<5 \mathrm{~cm}$ and not expanding. Surgical management is indicated if patient is hemodynamically unstable, haematomas $>5 \mathrm{~cm}$ or expanding. Surgical intervention in the form of haematoma evacuation, ligation of internal illiac artery, UAEor even hysterectomy. ${ }^{4,5}$

\section{CASE REPORT}

A 33 year old G2P1L1, previous normal vaginal delivery admitted in labour room at 38 weeks GA in active labour. ARM was done at $6 \mathrm{~cm}$ cervical dilatation. Within 20 mins patient complained of straining and delivered a healthy male baby of weight $3.710 \mathrm{~kg}$ without any complication. No evidence of cervical or vaginal tears noted. Right medio lateral episiotomy was sutured in layers.

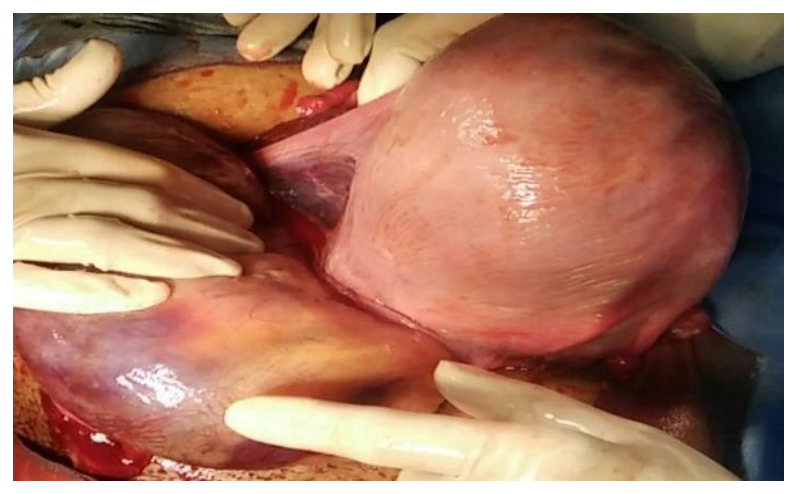

Figure 1: Rt. Sided broad ligament haematoma arising from rt side of broad ligament extending upto the perivesical space anterior to the uterus.

3 hours following delivery, patient complained of severe perineal and abdominal pain along with unable to void urine. O/E, patient looked pale, PR - 92, BP - 100/60, uterus well contracted above the level of umbilicus. Genital examination revealed episiotomy was intact, mild ooze from episiotomy skin site noted, no obvious vaginal or vulval swelling. On $\mathrm{P} / \mathrm{R}$ examination no obvious boggy mass felt. Pts vital further deterioted, fall of $\mathrm{Hb}$ $8.1 \mathrm{gm} \%$ from admission $\mathrm{Hb}-12.2 \mathrm{gm} \%$ was noted. Urgent transabdominal USG done showed a hypoechoic mass of $10 * 4.3 * 4 \mathrm{~cm}$ noted on the right side with a well contracted uterus deviated to the left. Broad ligament haematoma was confirmed. Based on pts haemodynamic instablity a decision of exploratory laparotomy was made.
Patients coagulation status was assessed by Thromboelastography test and adequate Blood products were arranged. Bladder catheterised with Foleys catheter and clear urine drained. Intraoperatively a huge haematoma $10 * 5 * 4 \mathrm{~cm}$ was seen anterior to rectus muscle. On entering the peritoneal cavity haematoma was found in right broad ligament extending into right paracolic gutter posteriorly and space of retzius anteriorly. Exact location of the bleeders could not be localised hence a decision of subtotal hysterectomy was done. 3 units PCV was transfused. 2 intraperitoneal drains placed in situ. Haematoma was non expanding hence left undisturbed. Postoperatively patient was managed in high dependency unit. Catheter was removed after 2 days, pt resumed her normal bowel bladder habits. Stitched removed on POD 10 and discharged. 4 weeks later patient was followed up with an USG abdomen which showed a resolving haematoma with size significantly reduced.

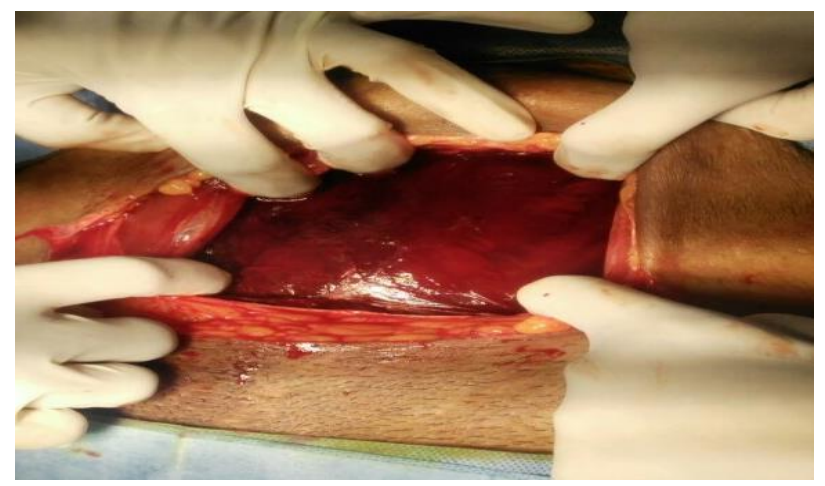

Figure 2: Broad ligament haematoma occupying the anterior compartment of abdomen; after splitting the rectus muscle.

\section{DISCUSSION}

Broad ligament haematoma is a relatively uncommon complication that can occur following a spontaneous vaginal delivery. Several cases of broad ligament hematomas were described in the early 1960s and 1970s. ${ }^{6}$

It is a serious maternal morbidity and can even lead to maternal death if timely diagnosis is not made. Its nonspecific clinical signs and symptoms ranges from mild pain to severe haemodynamic instablity. It can be silent and not cause any obvious vaginal bleeding. ${ }^{7}$ Clinical symptoms are vague with persistent perineal pain, urge to defecate, unable to void within first few hours of delivery. Murali et al reported a case where the patient presented with perineal heaviness and inability to pass urine. ${ }^{8}$

In another case reported by Nelofer patient presented with shock and needed resuscitation and volume replacement. Hence a high degree of clinical suscpicion is a must for diagnosis of such rare complication. Resuscitation, volume replacement, and surgical 
exploration are the key steps in the management. Imaging modalities like transabdominal/ transvaginal ultrasound confirms the diagnosis. For broad ligament haematomas conservative management is recommended. ${ }^{9}$

Imaging modalities like transabdominal ultrasound and MRI can help in confirming the diagnosis. It has been suggested that MRI depicts postpartum hemorrhage even in deep extraperitoneal regions where the hematoma is clinically non-apparent, and in addition it can delineate the extent of the hematoma ${ }^{10}$.

Broad ligament haematoma can be managed both conservatively and surgically depending on patients haemodynamic status, size and rate of haematoma expansion. Small non spreading ones can be managed conservatively however larger ones might need internal illiac artery ligation, UAE or even hysterectomy. Our patient was haemodynamically unstable after confirmed diagnosis and given the circumstances that the haematoma was expanding we decided on the surgical management i.e subtotal hysterectomy.

Funding: No funding sources Conflict of interest: None declared

Ethical approval: Not required

\section{REFERENCES}

1. Saleem N, Ali HS, Irfan A, Afzal B. Broad ligament hematoma following a vaginal delivery in primigravida. Pak J Med Sci. 2009;25:683-5.
2. Holtz RS. Massive hematoma of the broad ligament complicating cesarean section. J Int Coll Surg. 1959 Feb;31(2):188-91.

3. Addo V, Kokroe FA, Reindorf RL. Broad ligament hematoma following a Snake Bite. Ghana Med J. 2009;43(4):181-2.

4. Muthulakshmi B, Francis I, Magos A, Roy M, Watkinson A. Broad ligament haematoma after normal delivery. J Obstet Gynaecol. 2003;23:669-70.

5. Maxwell C, Gawler D, Green J. An unusual case of acute postpartum broad ligament haematoma. Australia N Z J Obstet Gynecol. 1997;37:239-41.

6. Bose K. A case of massive broad ligament hematoma following normal delivery. $\mathrm{Br} \mathrm{J}$ Clin Pract. 1963;17:591-4

7. Edmonds, Dewhurst's Textbook of Obstetrics \& Gynecology. (6 $6^{\text {th }}$ ed. $)$ Blackwell Science, London;2011.

8. Murali R, Hosni MM, Navaneetham N. A Rare Case of Broad Ligament Haematoma 24 Hours after Normal Vaginal Delivery. J Clin Case Rep. 2014;4(7):391.

9. Chohan A. Fundamentals of Obstetrics. $1^{\text {st }}$ ed. Lahore: M A R Publishers;2005:377.

10. Jain KA, Olcott EW. Magnetic resonance imaging of postpartum pelvic hematomas: early experience in diagnosis and treatment planning. Magn Reson Imaging. 1999;17:973-7.

Cite this article as: Yalla D, Nadar AN, Rani GU. Spontaneous broad ligament haematoma following a normal vaginal delivery - A case report. Int J Reprod Contracept Obstet Gynecol 2018;7:2521-3. 